\title{
Erratum to: Marinobacter persicus sp. nov., a moderately halophilic bacterium from a saline lake in Iran
}

\author{
Maryam Bagheri • Mohammad Ali Amoozegar • \\ Maryam Didari · Ali Makhdoumi-Kakhki • Peter Schumann • \\ Cathrin Spröer · Cristina Sánchez-Porro $\cdot$ Antonio Ventosa
}

Published online: 8 October 2013

(C) Springer Science+Business Media Dordrecht 2013

\section{Erratum to: Antonie van Leeuwenhoek (2013) 104:47-54 DOI 10.1007/s10482-013-9923-3}

On the protologue of the description of the new species, we cited incorrectly the culture collections of the type strain, which may be confusing for the validation and future citations of the type strain of this new species. They were correctly cited on the abstract of the article but not on the species description. On page 53 , column 1 , the end paragraph, lines $3-4$, the type strain should be cited as CCM $7970^{\mathrm{T}}$ (instead of CCM $7991^{\mathrm{T}}$ ) and IBRC-M $10445^{\mathrm{T}}$ (instead of IBRC $\left.10445^{\mathrm{T}}\right)$.
The online version of the original article can be found under doi:10.1007/s10482-013-9923-3.

M. Bagheri · M. A. Amoozegar $(\bowtie) \cdot$ M. Didari Extremophiles Laboratory, Department of Microbiology, Faculty of Biology and Center of Excellence in Phylogeny of Living Organisms, College of Science, University of Tehran, P.O. Box 14155-6455, Tehran, Iran

e-mail: amoozegar@ut.ac.ir

M. Bagheri · M. A. Amoozegar

Microorganisms Bank, Iranian Biological Resource

Centre (IBRC), ACECR, Tehran, Iran

A. Makhdoumi-Kakhki

Department of Biology, Faculty of Science, Ferdowsi

University of Mashhad, Mashhad, Iran

\author{
P. Schumann · C. Spröer \\ DSMZ-German Collection of Microorganisms and Cell \\ Cultures, Inhoffenstraße 7B, 38124 Braunschweig, \\ Germany \\ C. Sánchez-Porro · A. Ventosa \\ Department of Microbiology and Parasitology, Faculty of \\ Pharmacy, University of Sevilla, 41012 Sevilla, Spain
}

